\title{
Tea Catechin Inhibits Biofilm Formation of Methicillin-Resistant S. aureus
}

\author{
Yanying Zhao $\mathbb{D}$, Yun Qu $\mathbb{D}$, Junni Tang $\mathbb{D}$, Juan Chen $\mathbb{i}$, and Ji Liu \\ College of Life Science and Technology, Southwest Minzu University, Chengdu 610041, China \\ Correspondence should be addressed to Junni Tang; junneytang@aliyun.com
}

Received 24 September 2020; Revised 29 November 2020; Accepted 21 December 2020; Published 12 January 2021

Academic Editor: Alejandro Hernández

Copyright $\odot 2021$ Yanying Zhao et al. This is an open access article distributed under the Creative Commons Attribution License, which permits unrestricted use, distribution, and reproduction in any medium, provided the original work is properly cited.

\begin{abstract}
Staphylococcus aureus (S. aureus) is the most common pathogen causing infections from skin to systemic infections. The success of S. aureus infections can partially be attributed to its antibiotic resistance and to its ability to form biofilm. An increasing prevalence of methicillin-resistant $S$. aureus (MRSA) becomes a global public health problem in recent decades. Here, the effects of tea catechin extracts on the growth and biofilm formation of three MRSA strains were investigated. The results revealed that tea catechin extracts potently suppressed MRSA growth, and the minimal inhibitory concentration of tea catechin extracts against these MRSA strains was $0.1 \mathrm{~g} / \mathrm{L}$. Then, tea catechin extracts inhibited biofilm formation of these strains in a dose-dependent manner measured with a colorimetric method, and the inhibitory effect was also demonstrated by scanning electron microscopy assay. Moreover, adhesin genes biofilm-associated protein (bap), bone sialoprotein-binding protein ( $b b p$ ), collagen-binding protein ( $c n a)$, clumping factors $\mathrm{A}(c l f A)$, fibronectin binding protein $\mathrm{A}$ and $\mathrm{B}(f n b A$ and $f n b B)$, and intercellular adhesion gene $\mathrm{BC}$ $(i c a B C)$ were scanned, and the results shown that $f n b A$ and $i c a B C$ were present in these three strains. Furthermore, tea catechin extracts depressed $f n b A$ and $i c a B C$ expression in the strains. Therefore, inhibition of biofilm formation by tea catechin extracts probably was associated with downregulation of $f n b A$ and $i c a B C$ expression in these strains.
\end{abstract}

\section{Introduction}

Staphylococcus aureus (S. aureus) is among the most common pathogens that cause community- and hospital-acquired infections including mild skin infections, bacteremia, sepsis, toxic shock syndrome, and staphylococcal food poisoning [1-3]. The bacterium has special capacity to acquire resistance. Methicillin-resistant S. aureus (MRSA), often associated with hospital-acquired infections, is a type of Staphylococci that is resistant to beta-lactam antibiotics [4]. They are difficult to treat and related to a higher mortality rate than those caused by methicillin-susceptible $S$. aureus [5]. In addition, $S$. aureus are always encased in biofilms. Biofilms are aggregated structured communities of bacteria embedded in a matrix, which is composed of protein, DNA, and polysaccharide. During growth in biofilms, $S$. aureus may evade host defenses and become to be resistant to the action of antimicrobial drugs, making biofilm infections particularly difficult to eradicate $[6,7]$. Recent studies also showed that biofilms formed by $S$. aureus and MRSA strains may represent a hidden pathway for contamination of food and human handlers, by colonizing equipment and materials used in the food industry [8]. Biofilm formation in S. aureus isolates is facilitated via the microbial surface components recognizing adhesive matrix molecules (MSCRAMMs) and the biofilm-associated protein (bap) [9]. The protein components of MSCRAMMs have a high ability to interact with the host extracellular matrix proteins such as collagen-binding protein $(c n a)$, fibronectin binding proteins $\mathrm{A}$ and $\mathrm{B}\left(f_{n} b A\right.$ and $\left.f n b B\right)$, clumping factors $\mathrm{A}$ and $\mathrm{B}(\mathrm{clf} A$ and $c l f B)$, and bone sialoprotein-binding protein $(b b p)$ [10]. The accumulation phase of biofilm formation appears to be dependent on polysaccharide intercellular adhesin encoded by the icaADBC operon [11].

Green tea is a popular drink worldwide. The consumption of green tea has been shown to have many health benefits [12]. Catechins are the main constituents of green 
tea. There are four main catechins in green tea: (-)-epicatechin (EC), (-)-epicatechin-3-gallate (ECG), (-)-epigallocatechin (EGC), and (-)-epigallocatechin-3-gallate (EGCG). EGCG is the most abundant and accounts for approximately $59 \%$ of the total catechins [13]. Catechin has been recommended as a potential candidate for targeting antimicrobial agents due to a broad spectrum of antimicrobial properties [14]. However, the effect of catechin extracts on biofilm formation of MRSA has not been clearly elucidated. Thus, the influence of catechin on three MRSA isolates was investigated in the present study.

\section{Materials and Methods}

2.1. Bacterial Plate Counting. Three MRSA isolates (isolated from 229 ready to eat food samples including pot-stewed meat, spicy slips, cold dishes randomly collected from retail outlets in Chengdu, Sichuan province, China, in June 2015; MRSA strains and the type of staphylococcal cassette chromosome- (SCC-) mec were characterized by PCR analysis of mecA gene and SCC-mec type I to V as SCCmec type IVa), named 1 to 3 , were used in this study. Tea catechin extracts (Zhengzhou Green Banko Trade Ltd., China) were 2-fold gradient diluted to $0.8 \mathrm{~g} / \mathrm{L}, 0.4 \mathrm{~g} / \mathrm{L}, 0.2 \mathrm{~g} / \mathrm{L} 0.1 \mathrm{~g} / \mathrm{L}$, and $0.05 \mathrm{~g} / \mathrm{L} .2 \times 10^{5} \mathrm{cfu}$ MRSA isolates were inoculated in $250 \mathrm{~mL}$ tryptone soya broth (TSB) with or without different concentrations of tea catechin and incubated at $37^{\circ} \mathrm{C}$ for 24 hours. Then, $1 \mathrm{~mL}$ cell suspension was collected for viable plate counting. The minimal inhibitory concentration (MIC) value was determined as the lowest concentration of tea catechin that inhibited the growth of $100 \%$ bacteria [15], as recommended by the Clinical and Laboratory Standards Institute.

2.2. Biofilm Formation Assay. Biofilm formation was assayed by crystal violet staining in 96-well polystyrene microtiter plates (Costar, Cambridge, MA, USA) [16]. 105 CFU MRSA strains were inoculated into sterile 96-well polystyrene microtiter plates in the TSB medium containing $0.25 \%$ glucose (TSB-glucose) supplemented with $0.05 \mathrm{~g} / \mathrm{L}, 0.025 \mathrm{~g} / \mathrm{L}$, $0.0125 \mathrm{~g} / \mathrm{L}$, or $0 \mathrm{~g} / \mathrm{L}$ tea catechin and incubated for 24 hours at $37^{\circ} \mathrm{C}$. At the same time, the growth of each $S$. aureus isolate was monitored by resuspending the biomass of at least three wells per strain and the measurement of the $\mathrm{OD}_{600}$. The remaining wells (at least 3 per S. aureus isolates) were used for biofilm quantification. The supernatant with the planktonic bacteria was removed, and the remaining biofilm was dried. Then, surface-attached material was fixed with $100 \mu \mathrm{L}$ methanol for $10 \mathrm{~min}$. Thereafter, the biofilm was stained with $0.5 \%$ crystal violet for $20 \mathrm{~min}$ and solubilized with $30 \%$ glacial acetic acid for $15 \mathrm{~min}$. $\mathrm{OD}_{595}$ was measured to quantify the amount of biofilm. Wells filled with sterile TSB medium containing $0.25 \%$ glucose (TSB-glucose) supplemented with $0.05 \mathrm{~g} / \mathrm{L}, 0.025 \mathrm{~g} / \mathrm{L}, 0.0125 \mathrm{~g} / \mathrm{L}$, or $0 \mathrm{~g} / \mathrm{L}$ tea catechin were included in every experiment as a sterile control and served as blank for the $\mathrm{OD}_{600}$ and $\mathrm{OD}_{595}$ measurements. The amount of biofilm was normalized to the respective growth as assessed by $\mathrm{OD}_{600}$.
2.3. Biofilm Visualization by Scanning Electron Microscopy. MRSA strain 2 was selected and cultured overnight in TSB broth containing $0.25 \%$ glucose supplemented with $0.05 \mathrm{~g} / \mathrm{L}$, $0.025 \mathrm{~g} / \mathrm{L}, 0.0125 \mathrm{~g} / \mathrm{L}$, or $0 \mathrm{~g} / \mathrm{L}$ tea catechin extracts and then inoculated onto the glass coverslips in the wells of a 6-well plate (Costar, Cambridge, MA, USA). After static incubation at $37^{\circ} \mathrm{C}$ for 24 hours, the biofilm was washed with PBS, fixed with $2.5 \%$ formaldehyde at $4^{\circ} \mathrm{C}$ for 2 hours, and dehydrated in increasing concentrations of ethanol. The coverslips were fixed on aluminum stubs, covered with gold-palladium film, and examined in a FEI Inspect scanning electron microscope (S-4800, Hitachi, Japan).

2.4. PCR. PCR was employed to determine the distribution of $b a p, b b p, c n a, c l f A, f n b A$, and $i c a B C$ in these $S$. aureus isolates. After incubation overnight, $200 \mathrm{~mL}$ cell suspension was collected and centrifuged at $10,000 \mathrm{~g}$ for $15 \mathrm{~min}$. Total chromosomal DNA was extracted from the isolates using a DNeasy kit (Qiagen Inc., China) according to the manufacturer's instructions. All primer sets for adhesion genes were previously described by Tang et al. [17] as shown in Table 1 and were synthesized by Sangon company. PCR was performed with the following program: an initial denaturation step at $95^{\circ} \mathrm{C}$ for $5 \mathrm{~min}, 35$ amplification cycles, each at $95^{\circ} \mathrm{C}$ for $40 \mathrm{~s} ; 50 \mathrm{~s}$ at different annealing temperatures for different genes (Table 1); and $50 \mathrm{~s}$ at $72^{\circ} \mathrm{C}$, followed by an additional extension step of $10 \mathrm{~min}$ at $72^{\circ} \mathrm{C}$.

2.5. Real-Time Quantitative PCR. $2 \times 10^{5}$ CFU MRSA isolates were inoculated in $250 \mathrm{~mL}$ TSB and incubated at $37^{\circ} \mathrm{C}$ for 24 hours with or without $0.125 \mathrm{~g} / \mathrm{L}$ tea catechin. $1 \mathrm{~mL}$ cell suspension was collected for viable plate counting, and the cells in $1 \mathrm{~mL}$ cell suspension were also harvested by centrifugation at $10,000 \mathrm{~g}$ for $15 \mathrm{~min}$. Then, the bacteria were lysed by $200 \mu \mathrm{g} /$ $\mathrm{mL}$ lysostaphin in TE buffer $(10 \mathrm{mM}$ Tris- $\mathrm{HCl}, 1 \mathrm{mM}$ EDTA, $\mathrm{pH}$ 8.0). RNA was extracted using bacteria total RNA isolation kit (B518625, Sangon Biotech Co., Ltd., Shanghai, China) according to the manufacturer's instructions. In brief, bacterial cells were washed with $500 \mu \mathrm{L}$ diethyl pyrocarbonate-treated $\mathrm{ddH}_{2} \mathrm{O}$ in $900 \mu \mathrm{L}$ buffer Rlysis-B for $3 \mathrm{~min}$. Then, $200 \mu \mathrm{L}$ chloroform was added and centrifuged at $10,000 \mathrm{~g}$ for $5 \mathrm{~min}$. RNA was precipitated using $1 / 3$ volume ethanol, washed twice by $75 \%$ ethanol, and finally dissolved in $30 \mu \mathrm{L}$ diethyl pyrocarbonate-treated $\mathrm{ddH}_{2} \mathrm{O}$. Real-time quantitative PCR was used to detect the relative mRNA levels of $f n b A$ and $i c a B C$ in these MRSA isolates treated with $0.0125 \mathrm{~g} / \mathrm{L}$ tea catechin. The specific primers for icaBC are presented in Table 1 , and the primers for $f n b A$ were $f n b A-\mathrm{qF}$ : $5^{\prime}$-ACCGTCAAACGCAACACAAG- ${ }^{\prime}$ and $f n b A-\mathrm{qR}: 5^{\prime}$ TTCTGATGCCGTTCTTGGCT-3'. Protocols for PCR amplification were $120 \mathrm{~s}$ at $95^{\circ} \mathrm{C}$, followed by 39 cycles of $10 \mathrm{~s}$ at $95^{\circ} \mathrm{C}, 30 \mathrm{~s}$ at $55^{\circ} \mathrm{C}$, and $30 \mathrm{~s}$ at $72^{\circ} \mathrm{C}$. FtsZ (primers: FtsZ-F $5^{\prime}-$ TGAAGATGCAATCCAAGGTG- $3^{\prime}$ and FtsZ-R $5^{\prime}$ GTTAATGCGCCCATTTCT.TT-3') was used to normalize data. Real-time quantitative PCR was performed using a fluorescence temperature iCycler (Bio-Rad, Hercules, CA, USA). The threshold cycle (CT) was analyzed with a $2^{-\Delta \Delta C t}$ method [18]. 
TABle 1: Primers for amplification of the adhesin genes of Staphylococcus aureus.

\begin{tabular}{|c|c|c|c|}
\hline Gene & Primer sequences $\left(5^{\prime}-3^{\prime}\right)$ & Product sizes (base pairs) & Annealing temperature $\left({ }^{\circ} \mathrm{C}\right)$ \\
\hline bap & $\begin{array}{l}\text { GAGCCAAGACAAAGGTGAAG } \\
\text { GTAGCCATAGCACGGAACAT }\end{array}$ & 873 & 58 \\
\hline$b b p$ & $\begin{array}{l}\text { CTTAGCAGTTCAACAGGGTG } \\
\text { TTGGCTTTATTGTGATGGTC }\end{array}$ & 1662 & 56 \\
\hline cna & $\begin{array}{l}\text { CGATAACATCTGGGAATAAA } \\
\text { ATAGTCTCCACTAGGCAACG }\end{array}$ & 716 & 54 \\
\hline clfA & $\begin{array}{l}\text { AGTACCAAATGAGGCTGTTC } \\
\text { AAATGCTACTTCGTTGTCCC }\end{array}$ & 796 & 56 \\
\hline$f n b A$ & $\begin{array}{l}\text { TCCGCCGAACAACATACC } \\
\text { TCAAGCACAAGGACCAAT }\end{array}$ & 952 & 54 \\
\hline$f n b B$ & $\begin{array}{l}\text { TCTGCGTTATGAGGATTT } \\
\text { ACAGTAGAGGAAAGTGGG }\end{array}$ & 452 & 54 \\
\hline$i c a B C$ & $\begin{array}{c}\text { GCCTATCCTTATGGCTTGA } \\
\text { TGGAATCCGTCCCATCTC }\end{array}$ & 182 & 56 \\
\hline
\end{tabular}

2.6. Statistical analysis. Data were shown as mean \pm SEM, and the differences between tea catechin extracts treatments and controls were statistically analyzed using SPSS13.0 (SPSS, Chicago, IL, USA). Results were considered to be statistically significant where $P<0.05$.

\section{Results}

3.1. Bacterial Plate Counting. Growth of the three MRSA isolates in TSB broth containing tea catechin extracts at different concentrations was determined by viable plate counting as shown in Figure 1. Tea catechin extracts depressed all of the three MRSA isolates growth in a concentration-dependent manner. Especially, 0.8, 0.4, 0.2, and $0.1 \mathrm{~g} / \mathrm{L}$ tea catechin extracts absolutely inhibited bacteria with 24-hour incubation. Thus, the MIC of tea catechin extracts on these MRSA strains was $0.1 \mathrm{~g} / \mathrm{L}$.

3.2. Biofilm Formation Assay. After the biofilm was fixed with methanol and stained with crystal violet, it was solubilized in glacial acetic acid. The amount of biofilm biomass was measured using a colorimetric method. The result revealed that tea catechin extracts also inhibited biofilm formation of all the three MRSA isolates in a dose-dependent manner as shown in Figure 2. Therefore, tea catechin extracts potently impaired biofilm formation of these MRSA strains.

3.3. Scanning Electron Microscopy Assay. Strain 2 was selected for the following visual assay by scanning electron microscopy. As shown in Figure 3, there were a lot of biofilms accumulated on the coverslip without tea catechin extracts challenge. But tea catechin extracts suppressed the formation of biofilm to about $50 \%$ at the concentration of $0.0125 \mathrm{~g} / \mathrm{L}$, to about $15 \%$ at the concentration of $0.025 \mathrm{~g} / \mathrm{L}$, and a little of biofilm was observed at the concentration of $0.05 \mathrm{~g} / \mathrm{L}$. Therefore, consistent with colorimetric analysis, tea catechin extracts inhibited biofilm formation of MRSA strain 2.

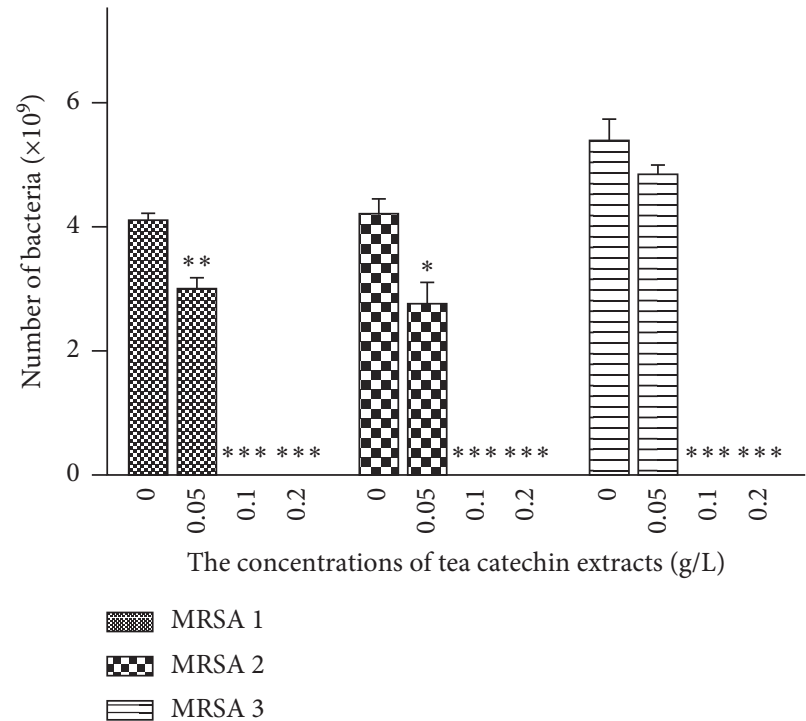

FIgURE 1: The effect of tea catechin extracts on the growth of methicillin-resistant $S$. aureus (MRSA) strains. $2 \times 10^{5} \mathrm{cfu}$ MRSA isolates were inoculated in $250 \mathrm{~mL}$ tryptone soya broth (TSB) supplemented with $0.8 \mathrm{~g} / \mathrm{L}, 0.4 \mathrm{~g} / \mathrm{L}, 0.2 \mathrm{~g} / \mathrm{L} 0.1 \mathrm{~g} / \mathrm{L}$, and $0.05 \mathrm{~g} / \mathrm{L}$ tea catechin extracts and incubated at $37^{\circ} \mathrm{C}$ for 24 hours. Then, $1 \mathrm{~mL}$ cell suspension was collected for viable plate counting. Data are mean \pm SEM of three independent experiments $\left({ }^{*} P<0.05\right.$, ${ }^{* *} P<0.01$, and $\left.{ }^{* * *} P<0.001\right)$.

3.4. Diversity of Adhesin Genes. Prevalence of adhesin genes $b a p, b b p, c l f A, c n a, f n b A, f n b B$, and $i c a B C$ was detected by PCR. The results in Table 2 show that the adhesin genes varied among different $S$. aureus strains. Genes $b a p, b b p$, $c l f A, c n a$, and $f n b B$ did not appear in the three strains, while $f n b A$ and $i c a B C$ were found in all these strains.

3.5. The Effect of Tea Catechin Extracts on fnbA and icaBC Gene Expression. Furthermore, to explore the mechanism underlying the effect of tea catechin extracts on biofilm formation of MRSA strains, the expression of $f n b A$, and $i c a B C$ was examined by real-time quantitative PCR. As summarized in Figure 4, the expression level of $f n b A$ gene 


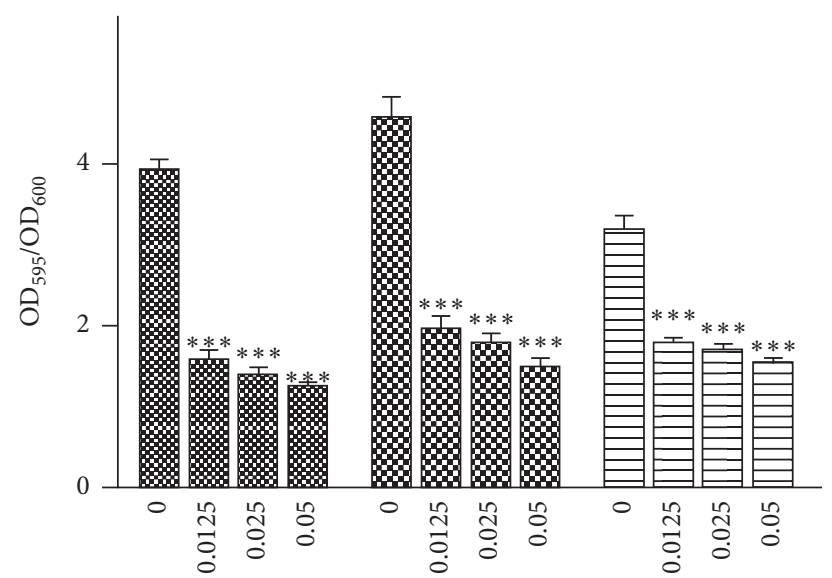

The concentrations of tea catechin extracts $(\mathrm{g} / \mathrm{L})$

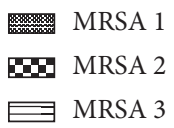

FIGURE 2: The influence of tea catechin extracts on the biofilm formation of MRSA isolates. Biofilm formation was assayed by crystal violet staining in 96-well polystyrene microtiter plates. Growth of each S. aureus isolate was monitored by resuspending the biomass of at least three wells per strain and the measurement of the $\mathrm{OD}_{600}$. The amount of biofilm was normalized to the respective growth as assessed by $\mathrm{OD}_{600}$. Data were the mean \pm SEM of three independent experiments $\left({ }^{* * *} P<0.001\right)$.

Control

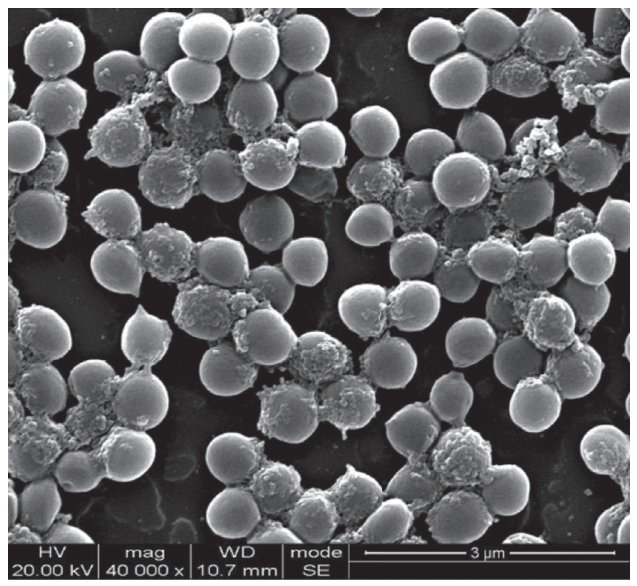

$0.025 \mathrm{~g} / \mathrm{L}$ tea catechin extracts

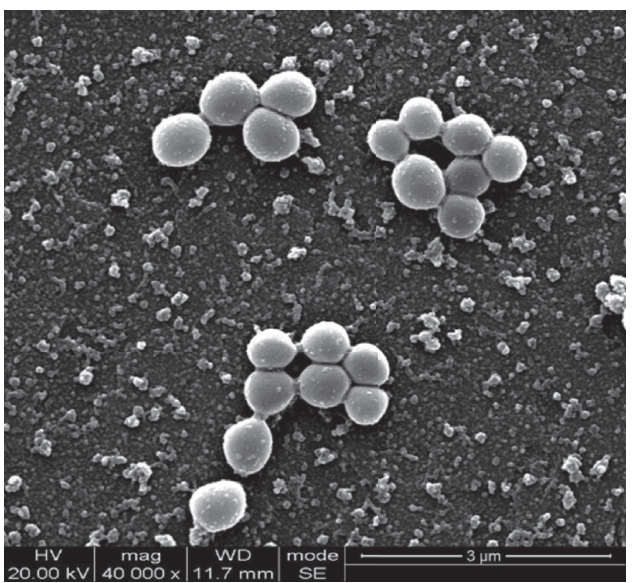

$0.0125 \mathrm{~g} / \mathrm{L}$ tea catechin extracts

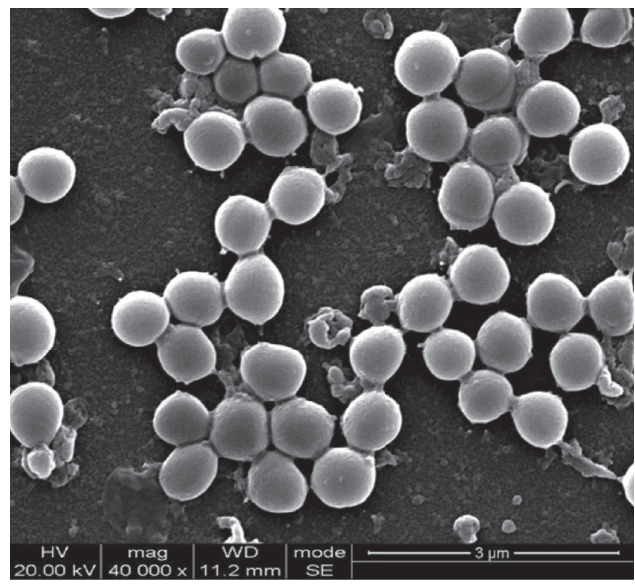

$0.05 \mathrm{~g} / \mathrm{L}$ tea catechin extracts

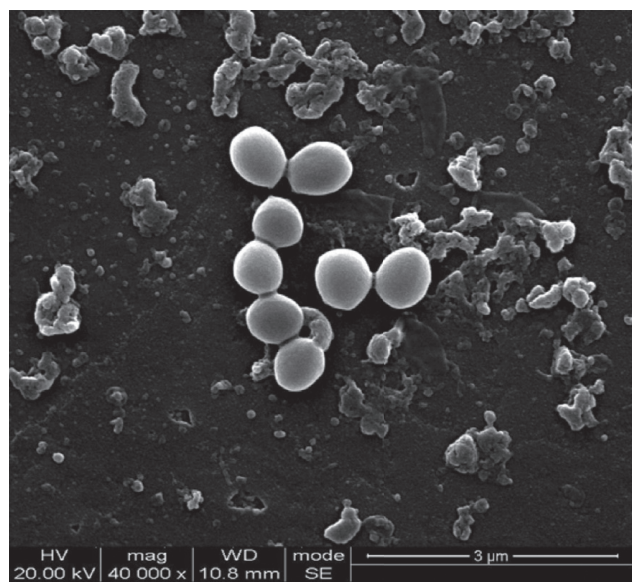

FIGURE 3: Scanning electron microscopy. MRSA strain 2 was cultured overnight in TSB broth containing $0.25 \%$ glucose supplemented with $0.05 \mathrm{~g} / \mathrm{L}, 0.025 \mathrm{~g} / \mathrm{L}$, or $0.0125 \mathrm{~g} / \mathrm{L}$ tea catechin extracts at $37^{\circ} \mathrm{C}$ for 24 hours, and the biofilm was fixed with $2.5 \%$ formaldehyde at $4{ }^{\circ} \mathrm{C}$ for 2 hours, dehydrated in increasing concentrations of ethanol, and examined using a scanning electron microscope. 
TABLE 2: Diversity of adhesin genes in the three MRSA strains.

\begin{tabular}{|c|c|c|c|c|c|c|c|}
\hline Gene/strains & bap & $b b p$ & clfA & cna & $f n b A$ & $f n b B$ & $i c a B C$ \\
\hline 1 & - & - & - & - & + & - & + \\
\hline 2 & - & - & - & - & + & - & + \\
\hline 3 & _- & _ & _- & - & + & _ & + \\
\hline
\end{tabular}

+ , the gene was found. -, the gene was not found.

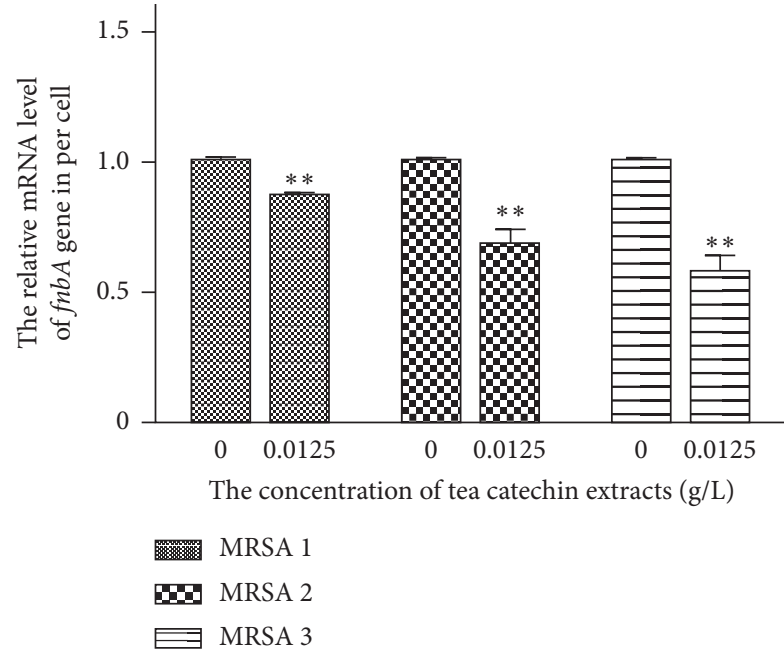

(a)

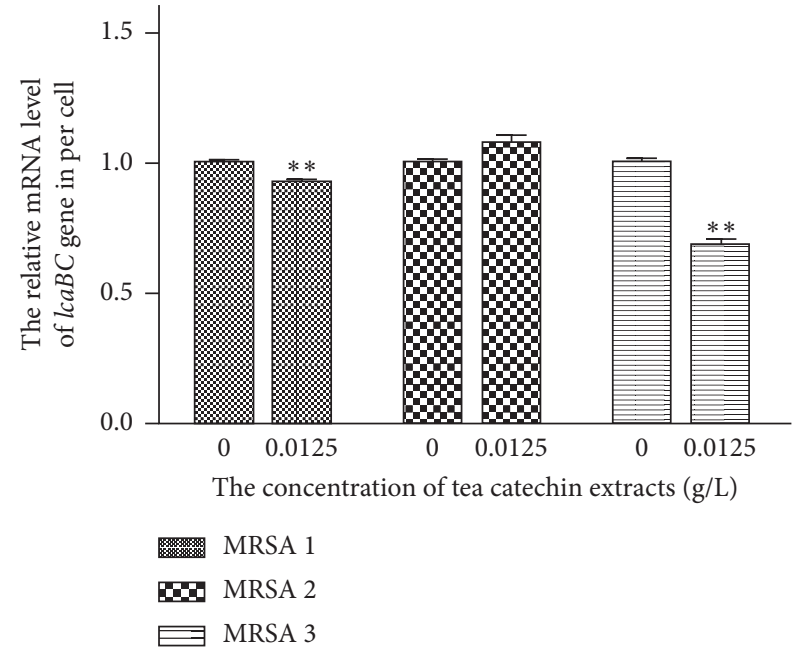

(b)

Figure 4: $f n b A$ and $i c a B C$ expression in MRSA isolates treated with tea catechin extracts. MRSA isolates were incubated with $0.0125 \mathrm{~g} / \mathrm{L}$ tea catechin extracts overnight. Real-time quantitative PCR was used to detect the relative mRNA level of $f n b A$ (a) and $i c a B C$ (b). Data were mean \pm SEM of three independent experiments $\left({ }^{*} P<0.05\right.$ and $\left.{ }^{* *} P<0.01\right)$.

was significantly decreased in strains 1,2 , and 3 with $0.0125 \mathrm{~g} / \mathrm{L}$ tea catechin extracts administration compared with controls. The expression of icaBC was also depressed in strains 1 and 3, but did not significantly vary in strain 2 . Therefore, tea catechin extracts inhibited fnb $\mathrm{A}$ and/or icaBC gene expression in these MRSA strains.

\section{Discussion}

S. aureus is an important nosocomial and food-borne pathogen, which causes infections ranging from skin to systemic infections [19]. The emergence of $S$. aureus resistant to antimicrobial agents has also provoked considerable concern due to its presence in associated foodstuffs [20]. The success of $S$. aureus infections can partially be attributed to its antibiotic resistance [9]. An increasing prevalence of MRSA leaves fewer effective treatment options, which has become a global public health problem in recent decades [4]. Nosocomial infections are often associated with MRSA, commonly transmitted either by direct contact with colonized healthcare workers or as a result of invasive medical procedures including surgeries and the introduction of medical implants [21]. There is a risk that MRSA have an inherent ability to form biofilms on various surfaces [8]. Bacteria in the biofilm matrix are more resistant to neutrophils and macrophages and are difficult to inhibit with antibiotics [22]. Therefore, in order to reduce the risk of colonization and dissemination of MRSA biofilm-producing strains, we investigated the inhibitory effect of tea catechin extracts on MRSA growth and found tea catechin extracts potentially inhibiting the growth of 3 MRSA strains, which suggested that tea catechin extracts can be used as a food preservative factor to prevent biofilm formation during food production.

In addition to antibiotic resistance, $S$. aureus infections associated with biofilm are difficult to treat because the biofilm matrix and phenotypic characteristics of the bacteria confer resistance to the host immune response and the action of antimicrobial drugs [6]. The major tea catechin extracts possesses a range of biological and medicinal properties, including antioxidant, anticarcinogenic, antiobesity, antibacterial, antiviral, and antienzymatic effects. Recently, Bai et al. demonstrated tea catechin extracts could inhibit the growth of Streptococcus mutans [23]. Wu et al. also confirmed tea catechin epigallocatechin-3-gallate (EGCG) against biofilm formation by $S$. mutans [24]. In the present study, all the 3 MRSA strains formed biofilm, and tea catechin extracts suppressed biofilm formation of all the strains in a dose-dependent manner with a colorimetric method. Furthermore, scanning electron microscopy assay demonstrated the inhibitory effect of tea catechin extracts on biofilm formation. Our results showed tea catechin extracts had a striking effect to inhibit biofilm formation and damage MRSA bacterial cells.

Fibronectin binding proteins $\mathrm{A}$ and $\mathrm{B}(f n b A$ and $f n b B)$ mediate adhesion of Staphylococcus aureus to fibrinogen, elastin, and fibronectin [25]. fnbA protein has been shown to 
promote biofilm formation on polystyrene surfaces in hospital- and community-acquired MRSA isolates [26]. In this study, tea catechin extracts decreased the expression level of $f n b A$ gene of these strains. Thus, the inhibitory effect of tea catechin extracts on biofilm formation was probably associated with $f n b A$ gene downregulation in these MRSA strains. At the same time, tea catechin extracts also depressed icaBC expression in strains 1 and 3 , which indicated that it impaired polysaccharide intercellular adhesin in these strains.

In conclusion, methicillin-resistant $S$. aureus (MRSA) is an important public health problem. Tea catechin extracts effectively inhibit 3 MRSA strain growth and impaired biofilm formation of these strains, which would be of great interest to the food industry. The inhibitory effect on biofilm formation was probably related to $f n b A$ (and icaBC) downregulation.

\section{Data Availability}

All data, models, and codes generated or used during the study are included within the article.

\section{Conflicts of Interest}

The authors declare no conflicts of interest.

\section{Authors' Contributions}

Y. Zhao and Y. Qu collected test data and drafted the manuscript. Y. Ma collected test data. J. Tang designed the study, interpreted the results, and revised the manuscript. C. Tang interpreted the results. Yanying Zhao and Yun Qu contributed equally to this work.

\section{Acknowledgments}

This work was jointly supported by the National Key Research and Development Program of China (2018YFD0500500), the Applied Basic Research Programs of Sichuan Province (2019YJ0261), the Sichuan Province Science Funds for Distinguished Young Scholar (2019JDJQ0017), the Open Fund of Key Laboratory and Bioresources Utilization (Dalian Minzu University), the Ministry of Education (KF2020008), and the Fundamental Research Funds for the Central Universities Southwest Minzu University (2020NTD04).

\section{References}

[1] G. Lina, Y. Piemont, F. Godail-Gamot et al., "Involvement of panton-valentine leukocidin--producing Staphylococcus aureus in primary skin infections and pneumonia," Clinical Infectious Diseases, vol. 29, no. 5, pp. 1128-1132, 1999.

[2] F. D. Lowy, "Staphylococcus aureus infections," New England Journal of Medicine, vol. 339, no. 8, pp. 520-532, 1998.

[3] Y. Le Loir, F. Baron, and M. Gautier, "Staphylococcus aureus and food poisoning," Genetics and Molecular Research, vol. 2, no. 1, pp. 63-76, 2003.
[4] M. Parker and J. H. Hewitt, "Methicillin resistance in Staphylococcus aureus," The Lancet, vol. 295, no. 7651, pp. 800-804, 1970.

[5] B. R. Lyon, J. L. Iuorio, J. W. May, and R. A. Skurray, "Molecular epidemiology of multiresistant Staphylococcus aureus in Australian hospitals," Journal of Medical Microbiology, vol. 17, no. 1, pp. 79-89, 1984.

[6] R. M. Donlan and J. W. Costerton, "Biofilms: survival mechanisms of clinically relevant microorganisms," Clinical Microbiology Reviews, vol. 15, no. 2, pp. 167-193, 2002.

[7] E. O’Neill, C. Pozzi, P. Houston et al., "Association between methicillin susceptibility and biofilm regulation in Staphylococcus aureus isolates from device-related infections," Journal of Clinical Microbiology, vol. 45, no. 5, pp. 1379-1388, 2007.

[8] D. Rodríguez-Lazaro, C. Alonso-Calleja, E. A. Oniciuc et al., "Characterization of biofilms formed by foodborne methicillin-resistant Staphylococcus aureus," Frontiers in Microbiology, vol. 93004 pages, 2018.

[9] M. Otto, "Molecular basis of Staphylococcus epidermidis infections," Seminars in Immunopathology, vol. 34, no. 2, pp. 201-214, 2012.

[10] S. A. Salman, N. S. Mariana, S. Zamberi et al., "Prevalence of adhesion and regulation of biofilm-rRelated genes in different clones of staphylococcus aureus," Journal of Biomedicine and Biotechnology, vol. 2012, Article ID 976972, 10 pages, 2012.

[11] K. E. Beenken, P. M. Dunman, F. McAleese et al., "Global gene expression in Staphylococcus aureus biofilms," Journal of Bacteriology, vol. 186, no. 14, pp. 4665-4684, 2004.

[12] N. Khan and H. Mukhtar, "Tea and health: studies in humans," Current Pharmaceutical Design, vol. 19, no. 34, pp. 6141-6147, 2013.

[13] A. Jigisha, R. Nishant, K. Navin, and G. Pankaj, "Green tea: a magical herb with miraculous outcomes," International Research Journal of Pharmacy, vol. 3, no. 5, pp. 139-148, 2012.

[14] W. C. Reygaert, "The antimicrobial possibilities of green tea," Frontiers in Microbiology, vol. 5, p. 434, 2014.

[15] A. Guzek, Z. Rybicki, and D. Tomaszewski, "In vitro analysis of the minimal inhibitory concentration values of different generations of anti-methicillin-resistant Staphylococcus aureus antibiotics," Indian Journal of Medical Microbiology, vol. 36, no. 1, pp. 119-120, 2018.

[16] T. Kuehnast, F. Cakar, T. Weinhaupl et al., "Comparative analyses of biofilm formation among different Cutibacterium acnes isolates," International Journal of Medical Microbiology, vol. 308, no. 8, pp. 1027-1035, 2018.

[17] J. Tang, J. Chen, H. Li, P. Zeng, and J. Li, "Characterization of adhesin genes, staphylococcal nuclease, hemolysis, and biofilm formation AmongStaphylococcus aureusStrains isolated from different sources," Foodborne Pathogens and Disease, vol. 10, no. 9, pp. 757-763, 2013.

[18] K. J. Livak and T. D. Schmittgen, "Analysis of relative gene expression data using real-time quantitative PCR and the 2- $\Delta \Delta$ CT method," Methods, vol. 25, no. 4, pp. 402-408, 2001.

[19] S. S. Chatterjee and M. Otto, "Improved understanding of factors driving methicillin-resistant Staphylococcus aureus epidemic waves," Clinical Epidemiology, vol. 5, pp. 205-217, 2013.

[20] D. Rodríguez-Lazaro, J. Ariza-Miguel, M. Diez-Valcarce, I. Fernandez-Natal, M. Hernandez, and J. Rovira, "Foods confiscated from non-EU flights as a neglected route of potential methicillin-resistant Staphylococcus aureus transmission," International Journal of Food Microbiology, vol. 209, pp. 29-33, 2015. 
[21] J. U. E. Sollid, A. S. Furberg, A. M. Hanssen, and M. Johannessen, "Staphylococcus aureus: determinants of human carriage," Infection, Genetics and Evolution, vol. 21, pp. 531-541, 2014.

[22] H. McCarthy, J. K. Rudkin, N. S. Black, L. Gallagher, E. O'Neill, and J. P. O'Gara, "Methicillin resistance and the biofilm phenotype in Staphylococcus aureus," Frontiers in Cellular and Infection Microbiology, vol. 5, no. 1, pp. 1-9, 2015.

[23] L. Bai, S. Takagi, T. Ando et al., "Antimicrobial activity of tea catechin against canine oral bacteria and the functional mechanisms," Journal of Veterinary Medical Science, vol. 78, no. 9, pp. 1439-1445, 2016.

[24] C.-Y. Wu, T.-Y. Su, M.-Y. Wang, S.-F. Yang, K. Mar, and S.-L. Hung, "Inhibitory effects of tea catechin epigallocatechin-3-gallate against biofilms formed from Streptococcus mutans and a probiotic lactobacillus strain," Archives of Oral Biology, vol. 94, pp. 69-77, 2018.

[25] M. Murai, H. Moriyama, E. Hata, F. Takeuchi, and J. Amemura-Maekawa, "Variation and association of fibronectin-binding protein genesfnbAandfnbBinStaphylococcus aureusJapanese isolates," Microbiology and Immunology, vol. 60 , no. 5, pp. 312-325, 2016.

[26] A. S. Abdulamir, S. A. Jassim, R. R. Hafidh, and F. A. Bakar, "The potential of bacteriophage cocktail in eliminating Methicillin-resistant Staphylococcus aureus biofilms in terms of different extracellular matrices expressed by PIA, ciaA-D and FnBPA genes," Annals of Clinical Microbiology and Antimicrobials, vol. 14, pp. 1-9, 2015. 